\title{
WHAT PLACE TEACHING IN HIGHER EDUCATION?
}

Bonnie Van der Steeg

Universities have a number of different objectives. Academic staff are expected to do research, administration and teach. Yet in terms of promotion and status, it is primarily the publications that matter (Light and Cox: 2001). However, for the vast majority of members of the university community - the students - it is the teaching and learning that has priority. I begin with the premise that, without wanting to downgrade the importance of research, teaching and learning should be of equal importance and status and that we should look to find ways of making them mutually reinforcing, rather than pulling staff in two directions.

My paper is divided into four sections:

I. Perspectives on university teaching

II. Teaching practice in other sectors of education

III. Teaching practice within higher education

IV. Suggestions for improving teaching and learning in universities

\section{Perspectives on university teaching}

\section{A. The ' $V T$ ' (visiting tutors) perspective}

In our institution, part-time lecturers and postgraduates who teach are called visiting tutors. As a group, we have been struck by the fact that we are actually set loose on students with next to no training. The fact that undergraduates and sometimes postgraduates are put into the hands of inexperienced, untrained postgraduates indicates to many that these students' education is not a main concern of the institution. Though the main lecture is usually given by a member of faculty, students have commented that they have had $\mathrm{PhD}$ students for the vast majority and in some cases all their seminars during 3 years. This doesn't mean that postgraduate research students cannot be good teachers, but their lack of experience will show up in a variety of ways:

-- A lack of confidence, which can be picked up by the students

-- An uncertainty about what the seminars are actually for and what they should be trying to achieve

-- Their vulnerability to complaints as students will tend to be more critical of the

$\mathrm{PhD}$ student that the main lecturer.

-- Difficulties in dealing with problems of group dynamics

-- Uncertainty about how to deal with 'problem' students

-- Lack of ideas for running seminars

-- Inability to implement any ideas effectively

The fact that postgraduates are for the most part left to get on with it unless there is a major revolt from the students, gives the impression that the institution is not 
overly concerned about what goes on in the actual seminars. This further reinforces the perception that teaching is not a priority.

\section{B. The student perspective}

Having talked to students from both my own institution and others, the overwhelming feeling is that teaching is low on the priority list for universities. Despite having very positive things to say about lectures and seminars in many cases, they still feel that there is something lacking. These are a few of the points:

1. The amount of time spent in lectures and seminars in the course of three years seems very small. One student commented that in a three year degree, they would have only one and a half years of teaching: a total of 60 weeks over 3 years. Students at two other universities spoke about having one lecture a week and then a meeting with their tutor every two weeks. They didn't even know the other people on their course.

2. Many students seriously struggle at university. Though there is some evidence that universities seem to be thinking more about how to induct new students into university study, (e.g. South Bank Study Guide) there is no consistency across universities. The impression given is that the university believes that they should be thrown in the deep end and left to get on with it. Now this may suit certain students, but as universities are opening their doors to more and more students, there will be an increasing amount of students who will not be able to cope with this approach. Talking to this year's first years, though they seem to be enjoying their course, they are overwhelmed by a number of aspects of studying.

-- They are not used to reading

-- They did not know how to go about even choosing their first essay title

-- A number of students had very poor attendance already in their first term

-- Some extremely poor essays were written, often showing serious language

problems even with students whose first language is English

-- The language is very new to them

-- They are unclear what is expected of them

While students value the independence of university study, we must be aware that becoming an independent learner does not happen overnight and that many students will need help in developing the appropriate skills. The key issue here is what is the university doing to help them. If this help appears not to be available, then this further reinforces the message is that teaching is not a priority.

3. A number of Third year students complained about an inconsistency in terms of how much help they get from different members of staff. It seems to be left to 
individual tutors to decide how much time they spend on seeing students and helping them with work such as their third year dissertation.

Though students themselves may blame individual members of staff for 'not caring', they seem to realise that the tutors are very busy and have a number of commitments. It is not a question of finding fault with individuals as such, but recognising that the evidence suggests that a lack of concern for the teaching and learning of undergraduates in particular is institutionalised. Tutors themselves have no training, they may have entered a career as an academic because of their interest in research and the research bias is reinforced by the university system as a whole. In addition, there is a serious lack of time as tutors' workloads continues to increase.

\section{Role of teaching in other sectors of education}

Teachers in other sectors find it astonishing that university teachers do not have to undergo any training and that they are considered qualified by virtue of their academic credentials. However, teaching is not something that can just be picked up in less time than it takes to train a MacDonald's worker. Trainee teachers have to go through an intensive training year before they are permitted to have the responsibility for educating the nation's young people. Isn't the education of all people in society of equal importance? And, there is much more to becoming a teacher than the training. Even after 22 years of teaching, I still don't feel that I have mastered the art. And this is true for many of my colleagues. We are constantly reflecting on our teaching and we are aware that becoming a teacher is a never-ending process.

I now turn to focus on the culture that exists within schools and colleges that fosters this reflection and critical assessment. Currently, in other sectors, the process of 'critical reflection' has been taken too far and teachers have come under enormous pressure to achieve the impossible. However, there are still positive points about how teachers think about their teaching. In order to give you an idea of what it is like, I will outline my experience of teaching in a London sixth form college.

The objectives: general aims and learning outcomes

A-level Teaching is clearly structured by the demands of the syllabus. This means that I know what my overall aim and objectives are. I have many criticisms of the A-level system, but that is a different issue that I will not deal with here. The point is that when I meet my classes for the first time, it is with a clear idea of what they need to learn. The syllabus provided by the exam board gives me the areas of knowledge that they will be tested on and also the skills that they will be required to develop. My job is to devise strategies that will ensure that they gain the required knowledge and skills and can demonstrate these in the exam or coursework.

Anthropology Matters J ournal, 2003-1

http:// www.anthropologymatters.com 
Implementing the objectives

I have a limited period of time to accomplish the aims and objectives, so work has to be divided up. We have to produce schemes of work in order to show that we will cover the necessary material. And the most important component of this is what we will do in each individual lesson. Lessons can take anything from a few minutes to several hours to prepare, not counting any refreshing we may have to do on the content itself. I have to think very carefully about how I am going to get the important ideas across. And in addition to the communication of ideas, I have to make sure that the students are learning the skills and are not bored! Therefore every lesson has to be different with a variety of activities. As you become more experienced you develop a greater knowledge of what 'works'. However, every group is different, every day is different, so I have to constantly reflect on what I am going to do, and never teach exactly the same lesson twice. It is only after many years of teaching that I have developed the ability to be flexible. If I sense that something is not working, that they seem to have lost concentration or they are not working well on a particular activity, I can now change in mid-lesson to do something else. I can also go with the flow if a lesson takes an unplanned, but useful turn. I am not the slave to the lesson plan. But, I still have in the back of my mind the general aims and learning outcomes of what I am trying to achieve.

Assessing the objectives

Teachers are constantly being assessed on whether or not they are meeting the objectives. The obvious way of doing that is exam results, but the assessment process goes on all the time. I need to somehow know if what I think I am teaching has been transformed into learning for the students. We have to recognise that no matter how well we know our material, no matter how clearly we have presented our material, the students may not have learned anything. This can be very frustrating and the temptation is to blame the student: they are not working hard enough, they are not listening, they are thick! However, as a teacher I have to accept that maybe the problem is that I need to change what I am doing. This tendency has gone too far now in my workplace in that teachers are blamed for everything and the responsibility is never the students. Nevertheless, we have to accept what students are like and devise strategies for getting them to be different. We will not succeed in all cases, but it is our job to try. It is this process, of realising that the teaching and learning are missing each other, that is the most important and is also the biggest mystery. How do students actually learn? Much research has been done on this and we still don't know the answer, so we just keep trying different strategies and sometimes it works and other times it doesn't! 


\section{Standards required}

Teachers are observed to see if they have met certain standards in their lessonsto see if they are effectively doing the things I outlined above. Here is an example of our lesson observation criteria. It shows the high expectations that we are required to try and live up to. The observation checklist at my college includes 22 criteria that are being assessed. They include:

-- Do the students understand what they are to achieve from the lesson?

-- Is students' interest being maintained?

-- Are individual needs identified and met?

-- Do students benefit from an appropriate variety of learning and teaching strategies?

-- Is teaching extending students knowledge and understanding?

-- Are equal opportunities/cultural issues promoted and addressed appropriately?

-- Are there regular checks that learning is taking place and constructive feedback is given?

Clearly, it is impossible to meet all these criteria in one lesson, but the teacher is aware of what they should be striving to do in all lessons.

\section{Teaching practice within higher education}

\section{Expectations}

In my experience, student expectations of tutors are much lower in higher education. There is not the in-built culture within the institution where tutors are reflecting on whether their students are actually learning and what they could do to improve their own teaching. The current situation tends to place the 'ball' of responsibility for learning totally in the students' court. If a student doesn't understand a lecture, can't take notes, doesn't understand a reading, doesn't speak in seminar or writes a bad essay, there is rarely a discussion of changing anything the tutor does. Now many tutors do question themselves and make changes - many postgraduate tutors do this regularly (they have to often because students have higher expectations of them). However, it is not an expectation of everyone. It all depends on the particular tutor. If someone is publishing regularly and bringing in research grant money, there would be no question of highlighting any lack of teaching ability. In addition, when employing people, what are the main criteria? Teaching ability or publishing potential?

Helping students to become independent

We might decide that at A-level, too many expectations are put on the teacher and not enough on the student. It is true that the current system is fostering a situation where teachers are spoon-feeding the students in order to ensure that their pass rate is high. In addition, there is a tendency to try and entertain and be 
popular because we are also judged on our retention rates. I would argue that the balance has to shift towards making the students more independent learners. In universities, however, I feel that the shift is too far in the other direction. We can't just expect students to become independent learners, we have to devise teaching strategies that will enable students to develop. We have to actually think carefully about the process of teaching and learning and not just carry on blindly, assuming that students are getting everything from lectures, seminars and readings and if they have problems it is their fault. We have to be more proactive. We have to actually care about our students' learning experience.

Identifying objectives

Another key difference is a lack of explicitness over the actual objectives of teaching. This is an important issue for postgraduate teachers. We are not sure what the department is expecting the students to achieve. What are the aims and objectives and do they change as the students progress through their education? It is impossible to reflect on our teaching when we do not know what we are supposed to be achieving. Some tutors may get very good reports, but are simply being judged on their personalities. But did the students actually learn anything?

\section{Suggestions for improving teaching and learning}

Finally, I present some suggestions for improving teaching and learning:

a. Discussion within departments about what the actual objectives of the teaching are. There should be a collective approach where the department has worked out the kind of knowledge and skills and capacities they would like the students to develop.

b. The different courses need to reinforce each other in the achievement of these objectives. For example, the department might identify key ideas that they want the students to have knowledge of or skills in. They then need to decide in which year to introduce these ideas. They may decide that there should be a progression such that certain ideas are introduced in the first year and then developed in the next two. The same is true of skills. What are the expectations of the students over the course of the three years?

c. The above process will require an awareness of differences between students. Some students may achieve the goals for the third year in the first year, so there needs to be room for differentiation. Also, if one of the objectives is for students to become independent and self-directed learners than there must be scope for this development, providing increasing amounts of opportunities to do so as they progress in their studies.

d. The whole process has to be monitored. Students' progress needs to be kept track of, not just in terms of exam marks or essay marks that are just left in the

Anthropology Matters J ournal, 2003-1

http://www.anthropologymatters.com 
file. In my sixth form college we have regular reviews with the students to discuss how we think they're doing and to work out with the students how they could improve. The students need to feel that we are concerned about them as individual learners.

e. Once tutors are clear about what the objectives are, then it will become easier to plan the teaching. They may even decide that the lecture/seminar format is not the most effective. Or they may devise different forms of assessment. This can only be done, though, once tutors know what the goal is.

f. The students need to be made aware of the objectives and the expectations we have of them. This will help put a stop to the tendency of the students thinking that they can get away with not attending or not doing much work. It would be impossible for learning strategies to work if the students are only there half of the time. Clear objectives and expectations would also help reduce the tendency of giving good reports to tutors who don't make them do anything or just have a good personality. They will learn to appreciate different tutors as long as they realise that the tutor is trying to help them achieve certain objectives. Tutors have different styles and personalities which are impossible to change. Teaching should not be a popularity contest.

g. The broad objectives need to be translated into manageable parts. So if one of the objectives is very broad, like getting the students to have a working understanding of the main theoretical approaches in anthropology, then that needs to be broken down. The same with skills. If the objective is to enable students to understand and use a wide variety of readings, then strategies have to be adopted over a number of courses. Each course and each lesson will have its own role to play in achieving the overall aims and objectives.

h. It will be impossible for tutors to implement the objectives if they have no training. Light and Cox (2001) identify two models of training: the tutor is left to work things out independently with informal advice from colleagues or the college-wide skills based approach where the institution runs a few generic courses that are supposed to add to the tutor's skills. But training has to be more than that. In addition, it needs to be subject specific or much of what is done will seem to be irrelevant.

Firstly they have to have a good understanding of what the objectives are and feel committed to them. Secondly, they need to have a repertoire of strategies, skills and techniques that they can use to achieve the various objectives within the context of their own courses. There will be many different ways of achieving the same objectives and tutors need to be able to be flexible in their approach. This is not easy to do. For visiting tutors, this process is very important and should be paid time and a training programme should be set out. 
i. Study skills need to be made more of a priority. There are many ways of doing this - as a separate course, integrated into courses, in the first term only, or spread over three years. But if we agree that a key objective is helping students to become independent learners and to know what they need to work towards, then study skills are essential. This is especially the case given what is happening to pre-university education where there is less and less independent learning being fostered because of the continual pressure of tests and exams.

j. We need to try and integrate research and teaching so that the two roles do not seem in conflict with each other. Possibilities of doing this would be to have more informal departmental seminars where tutors talked to students about their research and discussed their ideas with the students. Another idea would be to have a departmental magazine that was worked on by both staff and students. Goldsmiths has departmental research papers that they publish which uses the work of both staff and students, but this principle could be expanded. These ideas could supplement any use of a tutor's research as part of the course content which the students say they find very interesting.

k. My suggestions may require changes in the general way universities are funded and run. The key issue is the role of research. Often those who are good at research can't teach and there may be many people who would make excellent university teachers but are not interested or good at the game of getting things published. There is the idea of having two types of jobs, but then this could create divisions within departments. It would be preferable if people could keep the dual role. This would be effective if everyone felt that teaching was going to be important and if departments recruited staff on the basis of both research and teaching ability or potential. There could be some division of labour between people as long as it didn't create a status hierarchy. In addition, those who do have more difficulties with teaching, no matter what their publication record, should be willing to spend some time reflecting on their teaching. The whole process must be non-threatening, and I would favour more informal systems being put into place.

All of these ideas require one major change: that teaching students must be considered to be one of the primary roles of universities. If this is internalised into the ethos of all departments, then a creative process will be initiated and will happen automatically. If people do not have this view, then there is a danger that it will be forced upon people. We would then get all the problems that we have in other sectors of education where many teachers are very demoralised. A focus on teaching and learning should not mean more paper work, bureaucratic procedures and stressful assessments. If training and professionalisation do get forced on university departments from the top, with 'experts' coming in and evaluating and assessing and requiring evidence and quantitative measurements, it could be a disaster. It will kill any real reflection. At my college, workloads have increased and there is more and more pressure to produce evidence, such that it is getting more and more difficult to be a reflective teacher.

Anthropology Matters J ournal, 2003-1

http://www.anthropologymatters.com 
Low pay also demotivates, so any talk of professionalisation of teaching or reflective teaching must be firmly under the control of individual departments and be done in a supportive and non-threatening way. It needs minimal bureaucracy and must be accompanied by a reduction in workload and an increase in pay.

Bonnie VandeSteeg is both an anthropology research student in the field of environmental anthropology and a teacher with 22 years of experience in a variety of educational contexts. She has taught at Goldsmiths for three years, as a seminar leader for the anthropology of Religion course and as course organiser and lecturer for the Political Ecology course. She also teaches Philosophy and Religious Studies A-levels at a London sixth form college. She is currently undertaking research, together with Dr. Victoria Goddard of Goldsmiths, on Managing the Transition from A-Level to University. 